\title{
From 'Massification' to 'Popularization' -A Report on Deepening Reform of Higher Education in China under the Background of Globalization
}

\author{
Xiaoye Zhang \\ NENU., 2555 Jingyue Rd., Changchun City, \\ Jilin Province, PRC. \\ 872262439@qq.com
}

\author{
Mengmeng Zhang \\ NENU., 2555 Jingyue Rd., Changchun City, \\ Jilin Province, PRC.
}

\begin{abstract}
This paper aims to unveil how China's higher education deepen its reform in the context of globalization and personnel training, so as to widely explore the ways to gain and cultivate more innovative talents by implementing entrepreneurial $\&$ innovative education. This paper also finds that such measures as establishing a decentralized knowledge production model, strengthening the integration of education and information technology and constructing Internet model courses have actively promoted industry innovation and accelerated economic development while advancing education reform.
\end{abstract}

Keywords-Globalization; Popularization of higher education; Deepening reform; Entrepreneurialdinnovative curriculum system Double decentralized knowledge production

\section{INTRODUCTION}

Since the 21 st century, with the continuous globalization of international economy as well as frequent exchanges of trade, various kinds of cultures have collided and merged. The globalization and internationalization of higher education has also showed a trend of further rapid progress.

With the popularity of the Internet in the information age, the resources of higher education are flowing around the globe with an unprecedented degree, the space for international exchanges and international cooperation is gradually increasing. The higher education in China is moving toward the goal of "popularization", at the same time it encounters both great challenges and opportunities in this process.

As the beginning of the last century, China's modern higher education has delivered a large number of industryleading talents to the country in the process of "elitism." After more than 30 years of reform and opening up, China's higher education has made remarkable achievements.

In 2002, the gross enrollment rate of higher education institutions exceeded $15 \%$. China's higher education officially entered the stage of "massification." "China Education Development Report (2017)" shows that the gross enrollment rate in higher education in China has reached $42.7 \%$ in 2016 and is rapidly advancing to the "popularization" stage of higher education [1]. Under this background, the higher education catering to the development of the time has shifted from technical training to training innovative talents as an important goal of personnel training.

As far as the essence of education is concerned, technology is only a means to develop students comprehensive innovative qualities and abilities, and to cultivate their open, flexible, adventurous and brave entrepreneurial spirit in order to gradually shape their own personality. While educating people should be based primarily on their scholarship. Along with changing their training objectives, we must deepen the reform of personnel training modes, educational concepts, and educational tools so as to promote the rapid development of our higher education, then also create a powerful boost to the national economy.

\section{II. "ENTREPRENEURIAL \& INNOVATIVE" EDUCATION --- \\ DEEPENING THE REFORM OF PERSONNEL TRAINING MODE}

In the context of global integration, higher education is not simply an education of knowledge, but an innovative education, and an entrepreneurial education. Innovative talents carry the task of independent innovation of the country as well as shoulder the mission of rejuvenating the Chinese nation. It is particularly urgent, essential to deepen the reform and innovative education.

On the basis of intensifying alliances among colleges and universities as well as international cooperation across colleges and universities, both of which should further integrate education resources, raise the level of educational technology environment and infrastructure, speed up the updating of related learning systems, and emphasize the establishment of "Entrepreneurial \& Innovative" curriculum system, so as to cultivate creative and entrepreneurial talents.

Based on the characteristics of most of the innovation and technology originated in the interdisciplinary field, in the curriculum construction, we should first break through the line between professional education, general education, and humanities education, then set up an accessible curriculum system.

In the past, education for the purpose of students' skills training led to the lack of fostering creators. In addition to strengthening the management of objectives, it is also a need to relax the management of the process by establishing a 
foundation course for innovation and entrepreneurship. We introduced the campus into the "Mak-er space" as an implementation plan. Mak-er education is to integrate a variety of disciplines such as mathematics, art, etc. in the curriculum system, which aims to improve students' imagination, creativity and ability to address the problems.

At present, China's Tsinghua University, Tongji University and other groups have set up the Mak-er teams. Mak-er education integrates education, community and manufacturing equipment resources to provide innovative conditions for teams. With its autonomous learning complements as well as high-cooperation, teamwork, assistance, and even interdisciplinary teamwork, it focuses on the integrity of education, including setting up a scholarship for Mak-er's education and other policies. The cooperation, sharing and action it underlines are precisely new ways of training transdisciplinary innovation professionals. The learning space is transformed from the school's knowledge dissemination center into the space of practice and creation, where students propose creative solutions to problems and endeavor to achieve the goals with the assistance of numerous resources.

Compared with the traditional education, this nonacademic under-line learning model strives to offer students individualized education, which makes it much easier to hatch entrepreneurs and innovative personnel.

In terms of entrepreneurship education, the implementation of employment promotion programs and growth plans for college graduates is imperative.

First of all, with the policy support and service support, our government must optimize the entrepreneurial market environment so as to encourage more college students to start their own businesses.

Secondly, from the simple education and professional research in the past to highly connecte with the society, colleges and universities need to have both basic and applied research, personnel training aims to cater for needs of the market along with enterprises, and to provide knowledge as well as new technology directly to production.

Meanwhile, it is also necessary to track industry development and cooperate with enterprises, build up the school-enterprise cooperation base, which provides students with a wide range of practical training platform. And by making full use of innovative competitions, entrepreneurship training, etc., students learn to complete their training tasks through independent study, then fully enhance their entrepreneurial awareness and innovative spirit to guide their bold exploration.

Eventually, it is to be done definitively by developing "Internet $+"$ as well as incubating the project and ensure it success, setting up the foundation space, facilities and venture capital fund in the school to adapt to the new trend of economic development and education development so as to lead the university to become the lead of the overall social culture.

\section{THE ESTABLISHMENT OF DECENTRALIZED KNOWLEDGE PRODUCTION MODEL - DEEPEN THE REFORM OF RUNNING A SCHOOL}

In the context of higher education globalization and knowledge globalization, knowledge production is no longer part of the task of a single institution or a school researcher. Instead, it is derived in the research \&development departments of universities, research institutes and enterprises in diverse regions. If knowledge is still one-way flow through the way to participate in the production sector, there will be information asymmetry, waste of resources, other issues have become increasingly serious, competition in numerous institutions will lead to increasing pressure on colleges and universities.

However, if this diversified production of knowledge is integrated and utilized, a multidirectional combination of production, education and research will be established, that is, a new model of decentralized knowledge production will greatly enhance efficiency in transforming the production of knowledge into productive force.

The past theory-based teaching led to the lack of practical experience and innovative experience of students, the gap between graduation and employment is filled by enterprises, resulting in a long training cycle, training costs increase, and the scientific research results can not be timely transformed into business productivity.

Universities and research institutes and enterprises collaborate to set up a university science park so that the teaching achievements along with scientific research achievements can be rapidly transformed into productive forces. The progress of enterprises has driven the combination of scientific research and market.

At the same time, the science \& technology park has provided a practical platform and training base for personnel training in both colleges and universities. Furthermore, through cooperation with enterprises, teachers have access to demonstrate the rationality as well as the advancement of teaching contents, increase the level of teaching and research so as to promote discipline construction. Famous "Silicon Valley Model" is the first example of the combination of academia and the wealth community, besides, the close connection with industry also contributed to the success of teaching and research reform at Stanford University [2].

In terms of the regulation and control of university teachers resources, it breaks the boundaries between teacher and engineering \&technical personnel, both of them participate in the project and test the development and feasibility of the theory in practice, senior professional teachers are too stick to teaching first-line, offer support for students to participate in the project of science and technology development as well as research, which not only accelerated the transformation of scientific and technological achievements, while enabling students to quickly have the practical ability and innovative experience, in that case, both colleges and universities continue to enhance social services as a booster. 
In the development of "massification" to "popularization" of higher education, education promoted scientific and technological innovation in the industry. In contrast, industry participation in higher education also promoted scientific and technological innovation. Higher education provided strong productivity along with reliable guarantee for economic progress.

With China's deepening education reform policy, the prevailing mode of production, education and research integrated decentralized knowledge production has started the integration of knowledge among the government, enterprises, society and academia. By promoting the participation of social capital and resources, the government has also increased the introduction of high-quality educational resources at home and abroad to guide high-quality social along with business resources into universities and academics, encourage colleges and universities, science institutes, industry and trade enterprises to jointly establish the new mechanism for training innovative practical talents.

\section{THE INTEGRATION OF HIGHER EDUCATION AND INFORMATION TECHNOLOGY - DEEPENING THE REFORM OF TEACHING MODE}

As the Internet affects society and life more deeply, it is imperative for higher education to integrate the new information technology with the pace of the time, in order to deepen the reform of the teaching mode [3]. So under the background of the "Entrepreneurial \& Innovative" education" as well as the integration of production, study and research, a different model of classroom teaching came into being, which is the student-centered "Flipped Classroom" teaching mode. It formally reverses the normal course of the class or reverses the knowledge internalization as well as knowledge absorption in and out of the classroom when it comes to receiving knowledge. That is, reversing the process of transferring and internalizing learning content.

The new teaching mode of "Flipped Classroom" is benefited from that students can learn by themselves according to the self-study learning steps and learning habits through the information network, digital mobile service, and the students can make full use of the topics arranged by the teacher through the Internet's knowledge base, from which to find answers, learn from oneself and gain more knowledge.

In class, teachers can save more time and focus on the teaching of the key knowledge while students are available to work on the difficult problems, learn and discuss to enhance the purpose of learning and improve learning efficiency.

As for some extremely intense study projects which students barely solved by themselves after class, specialized lectures can be arranged in the classroom by the teacher in the form of case analysis, then students will expand. Flipped classroom subverts the traditional teaching mode, with the student-centered, teacher-assisted learning model, students are more likely to take the initiative to establish a learning group to overcome the difficulties in teaching stuff, rather than the "Inclusive Education" which depends entirely on teachers [4] in which case, teachers as the main body giving lessons has switched the role to organize the learning and help students, a mentor as it is.

\section{THE CONSTRUCTION OF INTERNET MODEL COURSE - DEEPENING THE REFORM OF TEACHING METHODS}

The most obvious trend of "higher education" from "massfication" to "popularization" is the informatization of education: student can learn by themselves, mobile learning and social learning gradually replace the relatively fixed \& single learning model, and students are more independent to choose the time when they want to learn, so that learning process is with more freedom and in deep sense; the dispersion and intermittency of learning time, the interactivity between work production along with learning become the characteristics of universal access to higher education. In the pristine teaching mode, the Internet has become a new means of teaching innovation, more international online course platform came into being.

So far, many countries, including the United States, Britain and Australia, have launched their own college online webbased course. The UK's "Future Learning" network teaching platform not only combines first-class universities, but also with the National Museum, the Museum and Cultural Association work together to launch a free online course that is available to the world [5]. China's Peking University, Tsinghua University along with other colleges and universities cooperated with the edX network teaching programs, launched their own free online course.

This series of courses based on the network as a medium as well as formed through recording and uploading online teaching platform is called "MOOC class." (Massive Open Online Course) In the flipped classroom, most of the students' prior independent learning content comes from the MOOC, which solves the students' effectiveness in distinguishing and using information and knowledge.

According to statistics of MOOC class learning, the total time of self-learning of students in the whole process is much longer than the learning time in the traditional classroom. Compared with the traditional classroom model, it has more advantages in training students to express opinions and solve problems.

At the same time, teachers should also adapt to the new education mode, promote more interactive online course, strengthen the construction of informatization and virtual learning communities on campus. The evaluation system of students transforms from a single paper evaluation into multiple and multi-angle evaluations. This "people-oriented" evaluation system is conducive to cultivating students' positive attitude towards learning and diversified creativity.

To sum up, in the face of increasingly fierce international competition and talent competition, higher education needs to face the market, deepen the reform and readjustment for the international community in order to meet the urgent market demand for talent quality, especially for innovative talents.

In the process of going from "massification" to "popularization", higher education is lean to emphasize the nature of educating people, improving all-round development 
and overall quality, focusing on teaching students according to their aptitude and establishing a people-oriented management concept.

Simultaneously, higher education should focus on the objective of building a modern economic system, strive for economic and social development, deliver innovative talents to major projects and emerging industries, serve the construction of an innovative nation, bring together industries and scientific \& technological forces, deepen education reform, then build an international competitiveness world-class university.

\section{REFERENCES}

[1] Dongping, Yang. Min, Yang. Shengli, Huang. Blue Book of Education: Annual Report of China's Education (2017). [M] Beijing: Social Sciences Academic Press (CHINA), 2017.

[2] Kangning, Wu. The Education Reform Issues in China, 1st ed. [M] Nanjing Normal University Press, 2015.

[3] Salman, Khan. The One World Schoolhouse: Education Reimagined, 1st ed. [M] Zhejiang People's Republishing House, 2014.

[4] Elmore, Richard F.Twenty leading Educators Reflect on the Work of School Reform, 1st ed [M]. The Commercial Press,2017.

[5] Peter. Scott, the Globalization of Higher Education, 1st ed. [M] Beijing: Peking University Press, 2009. 